\title{
LABOR FORCE MIGRATION, UNEMPLOYMENT AND JOB TURNOVER
}

\author{
Gary S. Fields*
}

$\mathbf{I}^{\mathrm{N}}$ recent years; economists have analyzed migration among geographic areas as a form of human investment whereby individuals are thought to incur present costs (both monetary and psychic) in the hope of receiving higher future earnings and other benefits. ${ }^{1}$ The essence of human investment theory is the assignment of a primary causal role to present values of spatial differences in economic opportunity as a determinant of migration. ${ }^{2}$

An issue of considerable importance is the translation of these general human investment notions into concrete theoretical and empirical terms. The problem centers on the multi-period investment horizon and consequently on measures of job stability and turnover when there is unemployment and uncertainty. Virtually all empirical studies to date have taken as an (inverse) index of economic opportunity the unemployment rate for the area in question. Previous researchers who have used the unemployment rate have encountered serious empirical difficulties. Some have found higher migration rates into high unemployment areas, ${ }^{3}$ while others have found the unemployment rate to be statistically insignificant as an explanatory

Received for publication April 21, 1975. Revision accepted for publication January 14, 1976.

* Financial support for this research was provided by the Economic Growth Center and the Irving Fisher Fund of the Department of Economics. I acknowledge with gratitude the research assistance of Julia Collins and Judy Oder and the helpful comments of Alan Gustman, Eric Hanushek, John Quigley and the referees of this REVIEw on an earlier draft.

1 The path-breaking paper in this area is that of Sjaastad (1962). Among other studies that have adopted the human investment approach to migration are those of Bowles (1970), Courchene (1970), DaVanzo (1972), Gallaway et al. (1967), Laber and Chase (1971), O'Neill (1970), Schwartz (1973), and Wertheimer (1970). These and other studies are reviewed in a valuable survey by Greenwood (1975).

2 For some time now, there has been little doubt about the primacy of economic factors in the migration decision. For instance, in 1967 Lansing and Mueller reported that $58 \%$ of a sample of migrants said they moved for purely economic reasons and another $14 \%$ partly for economic reasons. Only $23 \%$ moved for non-economic reasons and $5 \%$ gave no reason.

3 See Greenwood (1969), Rogers (1967), and Wadycki (1974). variable. ${ }^{4}$ In only a few studies has the unemployment rate been found to be an important deterrent to migration, and even then, only for certain population subgroups. 5 Thus, Greenwood (1975, p. 411) concludes: "One of the most perplexing problems confronting migration scholars is the lack of significance of local unemployment rates in explaining migration."

The empirical difficulty with the unemployment rate may well have a conceptual underpinning. A priori, we might suppose that unemployment rates are not very satisfactory measures of economic opportunity for potential migrants, who for reasons to be discussed below would presumably be more concerned with the probabilities of acquiring and retaining employment than with the average employment rate among all workers in the market. Thus, it would be expected that labor turnover variables (such as rates of new hires and layoffs) would play an important part in the explanation of migration.

In this paper, we show how labor turnover considerations can be integrated into the human investment theory of migration and demonstrate that such a model provides a much better explanation for migration rates into major metropolitan areas than the conventionally-used unemployment rate. The method used here may be of interest as well to researchers working on other human investment problems that also have a multi-period dimension.

\section{Unemployment and Labor Turnover in the Human Investment Theory of Migration}

The human investment theory of migration developed by Sjaastad (1962) and others was originally formulated without regard to unemployment; differences between labor markets in the present discounted value of future lifetime income $(P V)$ were taken as the primary

\footnotetext{
4 See Gallaway et al. (1967), Fabricant (1970), Courchene (1970), and Miller (1973).

5 See Lowry (1966) and Sommers and Suits (1973).
} 
determining factor. Individuals were thought to be more likely to migrate from places with low $P V \mathrm{~S}$ to places where $P V$ was higher, and high $P V$ labor markets would correspondingly be expected to have higher net in-migration rates $(N E T M I G)$ than low $P V$ ones. Thus the main labor market, hypothesis suggested by human investment models of migration is

$$
N E T M I G=f(P V), f^{\prime}>0 \text {. }
$$

In a world without unemployment, $P V$ would simply be the discounted sum of annual wages:

$$
P V 1=\sum_{t=1}^{T}\left[W_{t} /(1+r)^{t}\right]
$$

If we were to suppose that the wage will remain the same over one's lifetime and that the planning horizon is very long, the sum in (2) is equal to ${ }^{6}$

$$
P V 1=(W / r) \text {. }
$$

We turn now to the specification of $P V$ in a world of unemployment.

The simplest way of introducing unemployment into a human investment decision is to multiply the wage when employed by one minus the current unemployment rate:

$$
\begin{aligned}
P V 2 & =\sum_{t=1}^{T}\left[W(1-U) /(1+r)^{t}\right] \\
& =[W(1-U)] / r .
\end{aligned}
$$

This procedure has been followed in a study of migration in Canada by Laber and Chase (1971). Several other studies have introduced the unemployment rate as a separate variable determining expected $P V$ in a multiple regression explaining migration: ${ }^{7}$

$$
P V 3=g(W, U) \text {. }
$$

There are many reasons to believe that from the perspective of a potential labor force migrant the unemployment rate provides only an imperfect index of the tightness or looseness of alternative labor markets and, therefore, the explanatory power of models like (4) or (5) which use the unemployment rate would be limited. Most important is the fact that the unemployment rate pertains to the entire stock of workers and jobs, in particular including those

\footnotetext{
${ }^{6}$ This is the main explanatory variable used by Bowles (1970).

7 Among these are Courchene (1970), Fabricant (1970), Gallaway et al. (1967), Greenwood (1969), Lowry (1966), Miller (1973), Rogers (1967), Sommers and Suits (1973), and Wadycki (1974).
}

experienced workers who are secure in their present positions and those jobs which are already filled. Migrants, however, are presumably more concerned about turnover in the labor market and would be expected to pay much more attention to the rates at which hiring for new jobs is taking place, currently-employed workers are losing or leaving their jobs, and the like. ${ }^{8}$ Furthermore, these turnover variables are likely to be more sensitive indicators of differences in labor market conditions than is the unemployment rate. ${ }^{9}$ Finally, recent labor market research has found that the disaggregation of labor market information into component flows is helpful in understanding the unemployment experiences of different labor force subgroups at different points in time. ${ }^{10}$ Since migration is also influenced in an important way by anticipated accessions and separations of workers and jobs, similar gains in understanding might be expected by treating migration in terms of labor turnover.

For all these reasons, the unemployment rate may not be the best guide to employment conditions in alternative labor markets from the point of view of potential labor force migrants, and measures of labor turnover would appear preferable. The types of turnover variables used in this study are the rates of new hires and layoffs in each labor market.

The easiest way of including the probabilities of obtaining and remaining in a job is to enter

\footnotetext{
${ }^{8}$ For an excellent discussion of turnover in labor markets, see Hall (1972). The 1975 Economic Report of the President (pp. 102-105) offers a clear, concise discussion of labor turnover as a cause of unemployment differences. For a thorough analysis of the patterns of unemployment experiences among workers from a turnover perspective, see Hosek (1975).

9 This point is usually made in the context of cyclical variability in labor markets but it applies equally in the cross section.

10 For example, the unemployment rate of blacks is consistently double that of whites over the business cycle. Why this is has been analyzed in terms of racial differences in the duration of a spell of unemployment vs. the number of spells (see Smith and Holt, 1970), instability of workers of different races vs. the instability of the jobs available to those workers (Hall, 1972), and changing job permanence and labor force entries and exits over the cycle (Perry, 1972). Additional analysis reports that black employment is adversely affected by economic downturns to a greater relative extent than white employment (Gilroy, 1974). These and other studies, singly and together, suggest that the unemployment rate may be too gross a measure and additional understanding can be gained from a turnover approach.
} 
them as separate independent variables in a multiple regression along with the discounted wage:

$$
P V 4=f\left(W / r, P_{e u}, P_{u e}\right),
$$

where $P_{u e}$ is the probability of moving from unemployment $(u)$ to employment $(e)$ during a period given that one is unemployed at the beginning of the period (and similarly for $P_{e u}$ ). This empirical specification, while straightforward statistically, cannot be readily derived or interpreted in terms of the presumed behavior of individuals deciding whether or not to migrate. As we have seen, the human investment framework suggests that the relevant variable is the discounted present value of expected future income, which depends upon wage rates and the expected probabilities of being employed in each future period. One would not suppose that equation (6), which simply projects today's new hire and layoff rates into the future, would adequately reflect expectations of future employment probabilities. We must search for a conceptual apparatus that does.

One specific way of estimating future probabilities of being employed based on current data on job accessions and terminations is to regard the labor market as having two states employment and unemployment - with individuals facing a matrix of probabilities of remaining in or moving between the two states. The transition matrix may be written as

$$
P(t)=\left[\begin{array}{ll}
P_{e e}(t) & P_{e u}(t) \\
P_{u e}(t) & P_{u u}(t)
\end{array}\right]
$$

where $P_{i j}(t)$ is the probability of moving from state $i$ to state $j$ during time $t$. As a first approximation, we may suppose that individuals behave as if they take present transition probabilities and project them into the future as though the current values will prevail forever. By assuming constancy of the components of the $P(t)$ matrix, the mechanism determining the employment probability is a first order Markov process. ${ }^{11}$ As shown in Fields-Hosek

\footnotetext{
11 In models based on the unemployment rate (cf. equations (4) and (5) and footnote 7), it is implicitly assumed that individuals behave as if they calculate the current employment probability (approximated by one minus the unemployment rate), project it (rather than the transition probabilities) into the future as if today's values will prevail forever, and calculate present values from these data, to which they then respond in their migration decisions.
}

(1973), the results from Markov chains can be used to show that

$$
\begin{aligned}
P V 5=\left[W_{e} W_{u}\right] & {\left[I-\frac{1}{1+r} P^{T}\right]^{-1} } \\
& {\left[\begin{array}{ll}
E(0) \\
U & (0)
\end{array}\right] }
\end{aligned}
$$

where $W_{e}\left(W_{u}\right)$ is the wage one receives if he is employed (unemployed), $I$ is the identity matrix, $P^{T}$ is the transpose of $P$, and $E(0)$ and $U(0)$ are respectively one-zero variables denoting whether the individual is employed or unemployed at time zero. If we suppose that a new migrant would be unemployed initially (i.e., $U(0)=1, E(0)=0$ ) and he is ineligible for unemployment compensation $\left(W_{u}=0\right),{ }^{12}$ and if we denote the wage while employed by $W$, (8) may be solved to give an expected present value

$$
P V 5=[(1+r) / r] W\left[P_{u e} /\left(r+P_{u e}+P_{e u}\right)\right] .
$$

As noted above, among the most important questions asked of human investment models of migration is how much they contribute to our understanding of the amount by which various labor markets gain or lose workers on balance. Thus, the general hypothesis of these models is that labor markets with higher present values $(P V)$ would have higher net in-

Thus, the assumptions of the Markovian approach are no more stringent than those of conventional unemploymentoriented models, except insofar as it requires processing of three pieces of information (the wage, probability of getting a job, and probability of losing a job) rather than two (the wage and unemployment rate). For a brief but clear introduction to Markov processes, see Kemeny and Snell (1962).

12 An individual is ineligible to receive unemployment compensation if he quit his last job or is a new entrant or reentrant to the labor force. In recent years, between onehalf and two-thirds of the unemployed in any given month were not receiving unemployment_benefits for one reason or another. The assumption that a migrant will initially be unemployed is not crucial to the analysis. For migrants who have previously arranged for a job, and for whom $E(0)=1$, the expression for $P V$ is virtually the same as equation (9), with the one exception that $P_{u e}$ in the numerator of the last term is replaced by $\left(r+P_{u e}\right)$. Suppose that $e \%$ of migrants to a city move directly into a new job. Then the average Markovian $P V$, weighting the two present value expressions by $e$ and $(1-e)$, respectively, is $[(1+r) / r]$ $W\left[\left(P_{u e}+r e\right) /\left(r+P_{u e}+P_{e u}\right)\right]$, which differs from (9) by the addition of $r e$ in the numerator of the last term. We can take $r$ to be the same for every city. In the absence of data on $e$, we might reasonably expect that the inter-city variation in $r e$ is of the second order as compared with inter-city variability in $P_{u e}$. Hence, the error in measurement in equation (9), owing to neglect of moves with prearranged jobs, is presumably small. 
migration rates (NETMIG) than those with lower $P V S$ or, according to the alternative specifications given by equations (3), (4), (5), $(6)$, and (9), respectively,

$$
f(P V 1)=f(W / r)
$$$$
f(P V 2)=f((W / r)(1-U)) \ldots \ldots \ldots \ldots \ldots \text { multiplicative unemployment model }
$$

$$
\text { NETMIG }=f(P V 3):=f(W / r, U) \ldots \ldots \ldots \ldots \ldots \ldots \text { linear unemployment model }
$$

$$
f(P V 4)=f\left(W / r, P_{e u}, P_{u e}\right) \ldots \ldots \ldots \ldots \ldots \text { linear turnover model }
$$$$
f(P V 5)=f\left[[ ( 1 + r ) / r ] W \left[P_{u e} /\right.\right.
$$$$
\left.\left.\left(r+P_{u e}+P_{e u}\right)\right]\right] \ldots \ldots \ldots \ldots \ldots \ldots \ldots \text {. . . . . . . . }
$$

means uniform within cities, the SMSA is the smallest unit for which suitable data series on labor market conditions (i.e., unemployment
The specific hypotheses of this paper are that the labor turnover models (iv-v) are superior to models which rely on the rate of unemployment as an index of the likelihood of being employed in future time periods (ii-iii) and that the Markov transition model ( $v$ ) is superior to the linear turnover model (iv).

\section{Empirical Specification of the Model}

In this part of the study we seek to explain rates of net in-migration into twenty of the largest Standard Metropolitan Statistical Areas (SMSAs) in the United States. ${ }^{13}$ Data on migration between 1965 and 1970 are taken from the 1970 Census of Population and related to labor market conditions in the SMSAs. Rates of unemployment, new hires, and layoffs are drawn from various Labor Department sources for the base year, 1965. The sources of all data used in this study are given in the appendix.

The SMSA was selected as the unit of analysis for both conceptual and practical reasons. Large labor market aggregates, such as the 9 census regions or the 48 contiguous states, would seem to be unacceptably heterogeneous. ${ }^{14}$ While economic conditions are by no

\footnotetext{
13 The Bureau of the Census defines an SMSA as "an integrated economic and social unit with a large population nucleus. . . . The SMSA includes the county in which the central city is located, and adjacent counties that are found to be metropolitan in character and economically and socially integrated with the county of the central city." The SMSAs in the sample are Atlanta, Baltimore, Boston, Buffalo, Chicago, Cincinnati, Cleveland, Dallas, Detroit, Houston, Kansas City, Los Angeles, Milwaukee, Minneapolis, New York, Philadelphia, Pittsburgh, St. Louis, Seattle and Washington, D.C.

14 Of the studies which have used the human investment approach to study migration, some have studied migration between one area and the rest of the country (Minnesota in the case of Sjaastad, North-South by Bowles and Wertheimer), between 9 Census regions (O'Neill, DaVanzo, Schwartz), or between states or provinces (Gallaway et al.,
}

and turnover rates) are regularly published. The reason for the limitation to 20 is that costof-living series are available only for these cities and therefore these are the only ones for which real income (as opposed to undeflated dollar income) can be used as an explanatory variable. ${ }^{15}$

The dependent variable $(N E T M I G)$ is the number of civilian labor force members who had migrated to that SMSA between 1965 and 1970 less those who had migrated out of that SMSA during those same years, divided by the total 1965 labor force. It is therefore possible that a metropolitan area might have had negative net in-migration, and indeed many did.

The explanatory variables include measures of expected income in the SMSA when one is employed and the likelihood of employment. All variables pertain to $1965 .^{16}$ This was done in order to minimize the risk of simultaneous

Courchene, Laber-Chase). To my knowledge, the only study which has investigated migration involving units as small as SMSAs is that of Lowry.

15 Cost-of-living data are also available for Honolulu, San Diego, and San Francisco. Because of its special geographic position, Honolulu was excluded from the sample. San Diego and San Francisco were excluded because labor turnover data were not available for them.

16 In some SMSAs, local labor market conditions changed substantially over the migration period 1965-70 (e.g., widespread layoffs due to shutdowns in the aerospace industry in Seattle). In such cases, local labor market conditions in the later years of the period would be expected to provide a better explanation for labor force flows than would the 1965 data. Nonetheless, data for the later years have not been included as explanatory variables in this paper because rates of unemployment, new hires, and layoffs later in the period are very likely caused at least in part by migration in the earlier years. Simultaneous equations bias would consequently be expected in the net migration equations of this paper if later variables were included. By predating the explanatory variables, we avoid this bias, but we also understate the explanatory power of labor turnover based migration models. The use of a more complete model of the type described in footnote 17 would be expected to increase the proportion of variance explained. This awaits additional research. 
equations bias owing to the fact that migration influences contemporaneous economic variables as well as being influenced by them. ${ }^{17}$

The wage variable refers to the real median income in the SMSA of those who worked 5052 weeks in 1965 ( $R E A L Y 65)$. Income data on full-year workers are available only from the 1960 and 1970 Censuses for the preceding year. Therefore, $R E A L Y 65$ is approximated by the arithmetic average of median real income of full-year workers in the SMSA in 1959 and median earnings in 1969 and is then divided by 12 in order to be comparable with other variables which are measured monthly. Both the 1959 and 1969 figures are expressed in real terms after being deflated by the Bureau of Labor Statistics (BLS) Intermediate Budget for that city in the appropriate year. ${ }^{18}$

The unemployment rate $(U)$ pertains to the

civilian labor force. The labor turnover variables - monthly new hire rate $(N H)$ and layoff rate $(L)$ per 1,000 employees - are available for manufacturing establishments only. All data have been specified as averages of the monthly rates during 1965 .

Present values $(P V)$ were calculated from the figures on $R E A L Y 65, U, N H$, and $L$ to permit testing of the Markov model. REALY 65 is taken as a proxy for $W$ in equation (10v). The transition probabilities $P_{u e}$ and $P_{e u}$ are approximated as ${ }^{19}$

$$
\begin{aligned}
& P_{u e}=N H / U, \\
& P_{e u}=L /(1-U) .
\end{aligned}
$$

The present values were calculated using a monthly discount rate of $1 \%$.

Summarizing the above discussion, for the empirical formulation of the five forms of the human investment migration model corresponding to equation (10), we have

$$
\begin{aligned}
& f\left(R E A L Y 65 / r, \epsilon_{i}\right) \quad \ldots \ldots \ldots \ldots \ldots \ldots \ldots \ldots \text { simple wage, no unemployment model } \\
& f\left[(R E A L Y 65 \times(1-U)) / r, \epsilon_{i i}\right] \ldots \ldots \ldots \ldots \text { multiplicative unemployment model } \\
& N E T M I G=f\left(R E A L Y 65 / r, U, \epsilon_{i i i}\right) \ldots \ldots \ldots \ldots \ldots \ldots \ldots \ldots \ldots \ldots \ldots \ldots \ldots \text { linear unemployment model } \\
& f\left(R E A L Y 65 / r, N H, L, \epsilon_{i v}\right) \quad \ldots \ldots \ldots \ldots \ldots \text { linear turnover model } \\
& f[[(1+r) / r] R E A L Y 65[(N H / U) /(r+N H / \\
& \left.U+L /(1-U))], \epsilon_{v}\right] \ldots \ldots \ldots \ldots \ldots \ldots \ldots \text { Markovian turnover model. }
\end{aligned}
$$

17 For a careful examination of this question, see Muth (1971). There remains open, however, the possibility that pre-dating the wage, unemployment, and turnover variables would not remove all the bias, since it might be that migration, wage levels, and unemployment might all be determined by some as-yet-unspecified process which may be going on in the local economy. A thorough examination of this possibility requires a full model of demand and supply in local labor markets, perhaps along the lines pursued by Greenwood (1973), and lies well beyond the intended scope of the present paper.

18 The BLS publishes three series of budgets to permit inter-city comparisons of the cost of maintaining given standards of living for a family of four. The Intermediate Budgets for 1967 were selected for use here as most representative of the median family. These were in turn adjusted by the consumer price index for 1959 and 1969 to yield indices of relative living costs in different cities in the two years. These indices varied substantially, with the largest in 1959 being $16 \%$ greater than the smallest in that year, and in $196920 \%$ greater. These variations are substantial as compared with the range of values for nominal median incomes, which amounted to $25 \%$ in both years.

A referee of this REVIEw has taken issue with the real income measure used in this paper. Drawing upon a recent analysis of the BLS budget by Sherwood (1975), the referee has written: "The BLS budgets . . . are not intended to be used as precise deflators for comparing real income in different cities. . . Because the market baskets vary among the
We turn now to the results.

44 cities, the weights are shifted to reflect this, but at the subjective discretion of the budget maker." (Emphasis in the original.) We must then ask the empirical question: How imprecise are these deflators? If the imprecision were very substantial, we would expect to find the regression model performing worse in the presence of cost of living adjustments than in their absence. Yet, supplementary regressions similar to those reported in table 1, using undeflated rather than real incomes, were found to give markedly inferior results: the income variable was always negative and statistically insignificant and the $\boldsymbol{R}^{\mathbf{2}}$ was lower in each case. (These findings are available from the author upon request.) Thus, the use of the BLS Intermediate Budget is justified by its empirical performance. This accords with Sherwood's calculation that "removing the interarea weight variations from the intermediate standard budget has been found to have a small effect on interarea differences in overall consumption costs in the budgets."

19 From elementary probability theory, for two events $A$ and $B, P(A \cap B)=P(B) P(A \mid B)$. Letting $A$ be the event "become employed" and $B$ be the event "being unemployed," and dividing through by $P(B)$, we see that the probability of becoming employed given that one is unemployed $\left(P_{u e}\right.$ in (9)) is the probability of being unemployed and becoming employed (approximated by $N H$ ) divided by the probability of being unemployed $(U)$. Q.E.D. 
Table 1. - Regressions Explaining Net Labor Force Migration (NETMIG) into Twenty SMSAs, 1965-1970

\begin{tabular}{|c|c|c|c|c|c|}
\hline $\begin{array}{l}\text { Independent } \\
\text { Variable }\end{array}$ & $\begin{array}{l}\text { Simple Wage, } \\
\text { No Unemploy- } \\
\text { ment Model }\end{array}$ & $\begin{array}{l}\text { Multiplicative } \\
\text { Unemployment } \\
\text { Model }\end{array}$ & $\begin{array}{c}\text { Linear } \\
\text { Unemploy- } \\
\text { ment Model }\end{array}$ & $\begin{array}{c}\text { Linear } \\
\text { Turnover } \\
\text { Model }\end{array}$ & $\begin{array}{l}\text { Markov } \\
\text { Model }\end{array}$ \\
\hline & (i) & (ii) & (iii) & (iv) & (v) \\
\hline$R E A L Y 65$ & $\begin{array}{c}.00049 \\
(.00034)\end{array}$ & & $\begin{array}{l}.00044 \\
(.00035)\end{array}$ & $\begin{array}{l}.00016 \\
(.00023)\end{array}$ & \\
\hline$R E A L Y 65 \times(1-U)$ & & $\begin{array}{l}.00055 \\
(.00034)\end{array}$ & & & \\
\hline$U$ & & & $\begin{array}{l}-1.37331 \\
(1.30663)\end{array}$ & & \\
\hline$N H$ & & & & $\begin{array}{c}.03303 \\
(.01216)\end{array}$ & \\
\hline$L$ & & & & $\begin{array}{l}-.04425 \\
(.01719)\end{array}$ & \\
\hline$P V$ & & & & & $\begin{array}{l}.00055 \\
(.00012)\end{array}$ \\
\hline $\begin{array}{l}\text { Constant } \\
R^{2}\end{array}$ & $\begin{array}{l}-.28604 \\
.10\end{array}$ & $\begin{array}{l}-.30774 \\
.13\end{array}$ & $\begin{array}{l}-.20520 \\
.16\end{array}$ & $\begin{array}{l}-.13107 \\
.53\end{array}$ & $\begin{array}{l}-.17060 \\
.54\end{array}$ \\
\hline
\end{tabular}

Note: Standard errors are in parentheses. All figures are based on a monthly discount rate of $1 \%$.

\section{Empirical Results}

The regression results are reported in table 1. Two of the hypotheses of section I are strongly confirmed - the general empirical validity of the human investment approach to migration, and the specific superiority of the labor turnover approach over models based on the unemployment rate. The third hypothesis - the empirical superiority of a Markovian formulation of labor turnover as compared with a linear formulation - is not supported, but the two are found to provide virtually identical explanatory power.

Beginning with the simple wage, no unemployment model (i), we see that variation among metropolitan areas in median real incomes can explain only $10 \%$ of the variance in net migration rates. The coefficient on this variable, although positive, is not significantly different from zero. The apparent conclusion, therefore, is that present value of income alone provides an insufficient explanation for migration patterns, and other considerations (economic or other) must be brought in.

From a human investment perspective, the natural factor to consider next in the analysis is job stability. Models (ii) and (iii), which take as their measure of job stability the unemployment rate in the SMSA, in multiplicative and linear form, respectively, also perform poorly. None of the regression coefficients is significantly different from zero by conventional criteria and the coefficients of determination (0.13 and 0.16 , respectively) are correspondingly low. This is not surprising in light of the difficulties previously encountered in empirical work using the unemployment rate (see footnotes 3 and 4). We must look further.

Turning now to the linear and Markovian versions of the labor turnover models (iv and $\mathrm{v})$, we find a large part of the explanation. These models perform much better than did the unemployment rate in either of the alternative specifications (ii and iii). Both the new hire rate and the layoff rate have the hypothesized sign, and both are highly significantly different from zero. Furthermore, more than half the variance in net migration rates can be explained by these variables along with income, while equally uncomplicated unemployment models could explain nō more than $16 \%{ }^{20}$ These findings are reinforced by the results for the Markovian model. The present values computed from new hire and layoff rates according to equation (13v) are likewise found

\footnotetext{
20 Note that the dependent variable in this study is the migration rate and that the explanatory variables are strictly economic. Where similar coefficients of determination are found in elementary models in the literature, they usually involve at least one quasi-definitional relationship, as in the work of Lowry, for example, who explained the absolute number of migrants from origin $i$ to destination $j$ as a function of the population in $i$. The $R^{2}$ greater than 0.5 found here is a strong fit as compared with other empirical studies.
} 
to be highly significant, regardless of whether a monthly discount rate of $1 / 2 \%$ or $1 \%$ is used..$^{21}$ In short, labor turnover models seem to represent a substantial theoretical and statistical improvement over other equally uncomplicated economic models of migration based on unemployment rates.

It is also noteworthy that real income, which is the key explanatory variable in most migration studies, is not found here to add a statistically significant contribution. This suggests the possibility that it may be the availability of jobs, more than the incomes paid once in those jobs, which is the primary determinant of labor force migration. Further research on this question is clearly in order.

In comparing the explanatory power of the two versions of the labor turnover model, ,we find that the $R^{2}$ for the Markovian version is not significantly different from the figure obtained for the linear version. The Markovian framework has been advanced as one specific way of dealing with the more general problem of incorporating uncertainty into human investment analysis in an empirically verifiable manner. The results here confirm the utility of such an integration. Nevertheless, it should be remembered that the Markovian model is only one particular specification of a more general class of problems, and its failure to outperform a model with unclear theoretical support (the linearized version) should be interpreted accordingly.

\section{Conclusion}

This paper has sought to construct an intertemporal framework for approaching migration and to demonstrate its empirical relevance. Three principal points emerge from the analysis.

First, the validity of the human investment approach to migration is reconfirmed by these findings. It is clear that those factors which economic theory tells us ought to be important

\footnotetext{
21 Column (v) of table 1 reports the present value assuming a monthly discount rate of 0.01 . Qualitatively, the results are no different with other discount rates, except of course for the size of the coefficient. Using a monthly discount rate of 0.005 , for example, the corresponding equation is NETMIG $=-.11270+.00025 P V, R^{2}=.54$.

$(.00005)$
}

in explaining differential labor force migration flows (i.e., differences among labor markets in job opportunities and incomes) are in fact found to have the expected effects and are capable of explaining a considerable share of the variance.

Second, these findings also make clear that general human investment notions must be translated into specific empirical form with great care, for how it is done is seen to make a considerable difference in the explanatory power of the model. In particular, a labor turnover formulation gives a much different picture of the migration phenomenon than an approach based on unemployment rates.

And third, we find that the particular translation by a Markovian process offers a great simplification, for it permits us to compute from regularly published statistical sources a single number representing the value of the future rewards expected to be derived from a labor market, and this number "works." It may be worth noting that similar methods may be applied to other labor market problems of an intertemporal nature. Two possibly fruitful areas of application might be the assessment of the monetary rewards to taking up employment in alternative firms or industries or in training for alternative vocations or careers which differ in job stability.

This paper has not attempted to establish a "complete" model of migration by accounting for "nearly all" of the variance. To enhance the explanatory power of the model, future research might usefully proceed in at least two directions.

One course would be to continue to work with net migration. Within this framework, we might try to reduce the amount of unexplained variance by introducing other factors that have been found by previous researchers to be significant determinants of migration flows or that economic theory predicts would be of importance. The economic model itself may be amended, for instance, by allowing for risk aversion and imperfect information. Other non-economic factors like climate might be included as well.

Another potentially useful direction for further study would be to integrate the labor turnover approach into place-to-place models of 
gross migration. This would afford the advantage of recognizing explicitly two important determinants of migration flows: a) the costs of migration between specific origin-destination pairs, as well as the benefits, and b) spatial differences in the location of alternative opportunities for persons residing in different origins. With suitably disaggregated data on migration flows and turnover rates for labor force subgroups, place-to-place models might also help explain why gross migration flows into and out of labor markets are so much greater than the observed net flows.

The results of this paper indicate the usefulness of the labor turnover approach as the basis for explaining labor force migration. Hopefully, further research along the lines suggested above will enrich our understanding even further.

\section{APPENDIX}

\section{Definitions and Sources of Variables}

INMIG. Actual in-migration of labor force participants to the SMSA from all places (SMSAs or non-metropolitan areas) per 1,000 labor force participants in 1965.

OUTMIG. Actual out-migration of labor force participants from the SMSA to all places (SMSAs or nonmetropolitan areas) per 1,000 labor force participants in 1965.

$N E T M I G=I N M I G-O U T M I G$.

(Source of migration figures: 1970 Census of Population and Housing, Subject Reports: Mobility for Metropolitan Areas, PC(2)-2C. Source of labor force figures: Average of 1960 and 1970 labor force. Data for 1960 taken from 1960 Census of Population and Housing, Subject Reports: Mobility for Metropolitan Areas. Data for 1970 from 1970 Census of Population and Housing. Subject Reports: Mobility for Metropolitan Areas, PC(2)-2C, table 15.)

REALY65. Real median income in the SMSA of thos $\epsilon$ who worked 50-52 weeks per year. Approximated by $(Y 59+\mathrm{Y} 69) / 2$, where $Y 59=1959$ median income in the SMSA of those who worked 50-52 weeks/(1959 consumer price index $\times 1967$ total budget costs) and $Y 69=1969$ median earnings in the SMSA of those who worked 50-52 weeks/(1969 consumer price index $\times 1967$ total budget costs).

(Source of 1959 median income: 1960 Census of Population and Housing, Series PC(1), table 136: Median Income, males 14 and over, who worked 50-52 weeks in 1959. Source of 1969 median earnings: 1970 Census of Population and Housing,
Series PC(1), table 188: Median earnings of male experienced civilian labor force who worked 50-52 weeks in 1969. Source of consumer price index for 1959 and 1969: Handbook of Labor Statistics, 1970, table 128. Source of intermediate budget costs: Handbook of Labor Statistics, 1970, table 139.)

$N H / L .1965$ average new hire/layoff rate in manufacturing per hundred employees per month.

(Specific definitions may be found in BLS Handbook of Methods, 1971, Bulletin 1711. Source of all turnover variables: Employment and Earnings, May 1965.) Average 1965 civilian unemployment rate. (Source: 1972 Manpower Report of the President.)

\section{REFERENCES}

Bowles, S., "Migration as Investment: Empirical Tests of the Human Investment Approach to Geographical Mobility," this REvIEw 52 (Nov. 1970), 356362 .

Council of Economic Advisers, Economic Report of the President (Washington, D.C.: U.S. Government Printing Office, 1975).

Courchene, T. J., "Interprovincial Migration and Economic Adjustment," Canadian Journal of Economics 3 (Nov. 1970), 550-576.

DaVanzo, J., An Analytical Framework for Studying the Potential Effects of an Income Maintenance Program on U.S. Interregional Migration (Santa Monica: Rand Corporation, R-1081-EDA, Dec. 1972).

Fabricant, R. A., "An Expectational Model of Migration," Journal of Regional Science 10 (Apr. 1970), 13-24.

Fields, G. S., and J. R. Hosek, "Human Investment Decisions, Labor Market Choice, and Unemployment," paper presented at the Dec. 1973 meetings of the Econometric Society, New York.

Gallaway, L. E., R. F. Gilbert, and P. E. Smith, "The Economics of Labor Mobility: An Empirical Analysis," Western Economic Journal 5 (1967), 211223.

Gilroy, C. L., "Black and White Unemployment: the Dynamics of the Differential," Monthly Labor Review 97 (Feb. 1974), 38-47.

Greenwood, M. J., "An Analysis of the Determinants of Geographic Labor Mobility in the United States," this REVIEW 51 (May 1969), 189-194.

Interaction," Environment and Planning 5 (1973), 91-112.

States: A Survey," Journal of Economic Literature 13 (June 1975), 397-433.

Hall, R. E., "Turnover in the Labor Force," Brookings Papers on Economic Activity 3 (1972), 709-756.

Hosek, J. R., Unemployment Patterns Among Individuals (Santa Monica: Rand Corporation, R-1775EDA, Aug. 1975). 
Kemeny, J. J., and L. J. Snell, Mathematical Models in the Social Sciences (New York: Blaisdell, 1962), 128-131.

Laber, G., and R. X. Chase, "Interprovincial Migration in Canada as a Human Capital Decision," Journal of Political Economy 79 (July/Aug. 1971), 795804.

Lansing, J. B., and E. Mueller, The Geographic Mobility of Labor (Ann Arbor: Institute for Social Research, University of Michigan, 1967).

Lowry, I. S., Migration and Metropolitan Growth: Two Analytical Models (Los Angeles: Institute of Government and Public Affairs, UCLA, 1966).

Miller, E., "Is Out-Migration Affected by Economic Conditions?," Southern Economic Journal 39 (Jan. 1973), 396-405.

Muth, R. F., "Migration: Chicken or Egg?," Southern Economic Journal 37 (Jan. 1971), 295-306.

O'Neill, J. A., The Effects of Income and Education on Inter-Regional Migration, Columbia University, un published Ph.D. dissertation, 1970.

Perry, G. L., "Unemployment Flows in the U.S. Labor Market," Brookings Papers on Economic Activity 2 (1972), 245-278.

$\rightarrow$ Rogers, A., "A Regression Analysis of Interregional
Migration in California," this REVIEw 49 (May 1967), 262-267.

Schwartz, A., "Interpreting the Effect of Distance on Migration," Journal of Political Economy 81 (Sept./Oct. 1973), 1153-1169.

Sherwood, M. K., "Family Budgets and Geographic Differences in Price Levels," Monthly Labor Review 98 (Apr. 1975), 8-15.

Sjaastad, L., "The Costs and Returns of Human Migration," Journal of Political Economy 70 (Oct. supplement, 1962), 80-93.

Smith, R. E., and C. C. Holt, "A Job-Search-Turnover Analysis of the Black-White Unemployment Ratio," Proceedings of the 23rd Annual Meeting of the Industrial Relations Research Association, 1970, 76-86.

Sommers, P. M., and D. B. Suits, "Analysis of Net Interstate Migration," Southern Economic Journal 40 (Oct. 1973), 193-201.

$\rightarrow$ Wadycki, W. J., "Alternative Opportunities and Interstate Migration: Some Additional Results," this REVIEW 56 (May 1974), 254-257.

Wertheimer, R. II, The Monetary Reward of Migration Within the U.S. (Washington, D.C.: The Urban Institute, 1970). 